In der Rubrik „Literatur kompakt" werden die wichtigsten Originalarbeiten aus der internationalen Fachliteratur referiert.

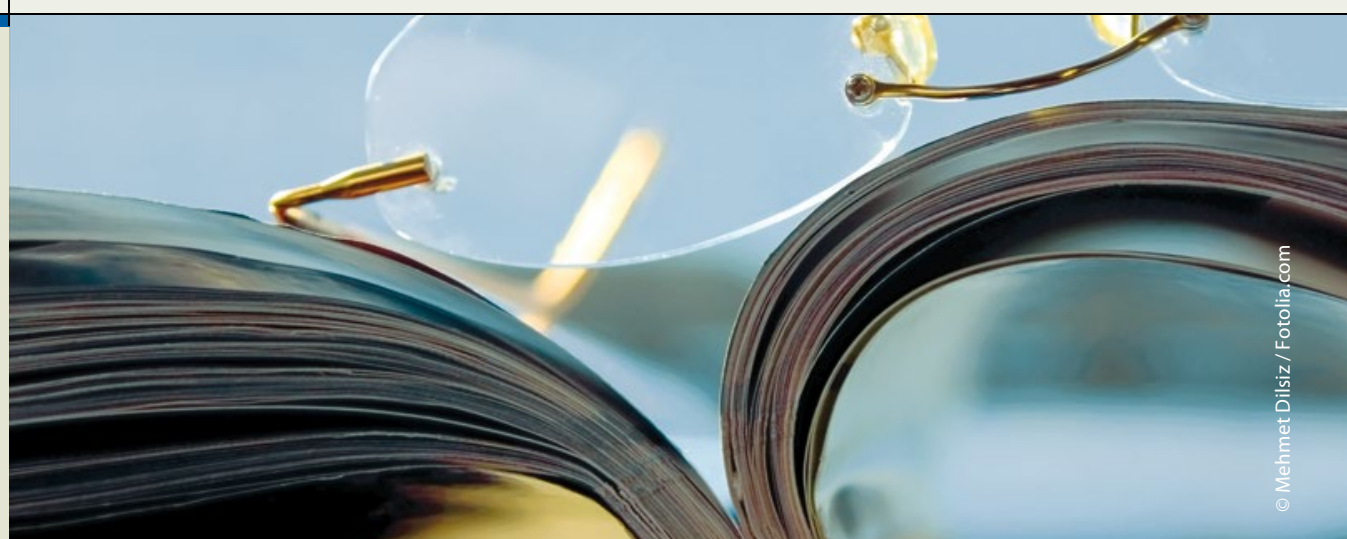

\section{Photothermolyse soll Akne bekämpfen}

\section{Eine experimentelle Aknetherapie auf der Basis thermischer Schädigung von Talgdrüsenfollikeln ist in zwei kleinen klinischen Studien erfolgreich getestet worden.}

$\mathrm{D}$ ie Pathophysiologie der Acne vulgaris lässt vermuten, dass die Zerstörung von Talgdrüsen ein Weg zu einer wirksamen Behandlung der Hautkrankheit ist. US-amerikanische Forscher haben nun ein spezielles Verfahren untersucht, dass die Schädigung der Talgdrüsen durch einen thermischen Reiz bewirkt.

Bei der untersuchten Methode handelt es sich um eine selektive Photothermolyse der Talgdrüsenfollikel. Dabei werden Mikropartikel mit einem $120 \mathrm{~nm}$ durchmessenden Silikonkern und einem $15 \mathrm{~nm}$ dicken Goldmantel durch mechanische Vibrationen in die Talgdrüsen einmassiert. Anschließend setzt man die Partikel Licht von $800 \mathrm{~nm}$ Wellenlänge aus einem Diodenlaser aus und regt sie damit zu einer starken optischen Absorption an. Das soll schließlich die thermischen Schäden an den Talgdrüsen verursachen.

Ob die einmassierten und bestrahlten Partikel den gewünschten thermischen Effekt in den Talgdrüsen und möglichst nur dort auslösen, wurde in Versuchen in vivo sowohl mit Schweinen als auch mit Menschen überprüft. Histologisch konnten die gewünschten Effekte verifiziert werden. Unter dem Mikroskop zeigte sich eine thermische Verletzung

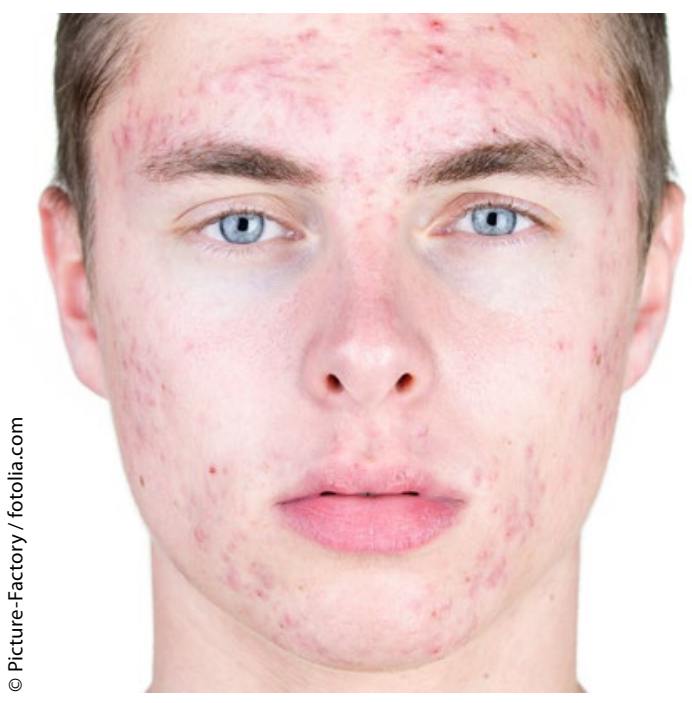

Photothermolyse:

Hoffnung für

Aknepatienten? der Follikel und Drüsen. Die dadurch ausgelöste Entzündung erwies sich als mäßig. Einen Monat später waren die Goldpartikel verschwunden, die Aufnahme in andere Organe war laut den Ergebnissen der Studie zu vernachlässigen.

In zwei randomisierten und kontrollierten Studien an denen 50 respektive 51 Probanden mit mäßiger bis schwerer Akne beteiligt waren, testeten die Wissenschaftler das Verfahren unter klinischen Bedingungen. Die Probanden wurden dafür dreimal im Abstand von ein bis zwei Wochen der geschilderten selektiven Photothermolyse unterzogen. Im ersten Versuch diente eine standardisierte zwölfwöchige Reinigungsprozedur als Vergleichstherapie. Gegenüber dem Ausgangszustand hatte sich die Zahl der entzündlichen Hautveränderungen unter der Photothermolyse nach 28 Wochen um rund $60 \%$ reduziert, verglichen mit $16 \%$ nach der standardisierten Hautreinigung.

Im zweiten Versuch erhielt ein Teil der Probanden eine Scheinbehandlung. Auch hier führte die Photothermolyse zu besseren Ergebnissen. Nach 16 Wochen waren die Akneläsionen um mehr als $50 \%$ vermindert. Das Minus nach der Scheintherapie betrug $30 \%$.

Fazit: Sowohl in In-vivo- wie in zwei kleinen klinischen Studien hat die selektive Photothermolyse die in sie gesetzten Erwartungen erfüllt: Die Zahl der Akneveränderungen an der Haut ging deutlich zurück.

Dr. Robert Bublak

Paithankar DY et al. Acne Treatment Based on Selective Photothermolysis of Sebaceous

Follicles with Topically Delivered LightAbsorbing Gold Microparticles. J Invest Dermatol 2015; 135: 1727-34 